\section{Afinal, a estagnação secular do capitalismo?}

Robert J. Gordon. The rise and fall of American growth.

Princeton (NJ), Princeton University Press, 2016. 784 pp.

\section{Luiz Carlos Bresser-Pereira}

A tese da tendência secular à estagnação do sistema capitalista foi esboçada por Adam Smith e teorizada por David Ricardo e Marx. Para Ricardo, a partir da previsão da queda no longo prazo da taxa de lucro devido à diminuição da produtividade da terra em função da ocupação de terras cada vez menos férteis; para Marx, como consequência da queda da produtividade do capital. Ainda que os dois modelos tenham sido lógicos, sua premissa - a queda da produtividade devido a rendimentos decrescentes - afinal não aconteceu. As contratendências à queda da taxa de lucro - que Marx considerou, mas sem a devida importância, porque não mostravam força no seu tempo - prevaleceram, e a teoria liberal permaneceu satisfatória para as empresas investir no longo prazo.

\section{Lado da demanda}

As teorias da estagnação derivam tanto de problemas do lado da oferta, envolvendo queda da produtividade, quanto do lado da demanda. Ainda que Marx náo tenha deixado uma teoria do colapso do capitalismo pelo lado da demanda, deixou uma pista da maior importância: a tendência à superprodução ou ao subconsumo, que seria intrínseca ao capitalismo. Conforme observou Cipolla (2013, p. 68), "em $O$ capital o ritmo de expansão do capital, possibilitado pelo sistema de crédito, rompe o equilíbrio entre oferta e demanda levando à fase especulativa e ao seu posterior colapso". Isso ocorre porque Marx percebeu com clareza que o capitalismo é apenas uma economia de mercado, mas uma economia monetária na qual a mais-valia expressa em dinheiro é o essencial. O capitalismo não implica a troca $M-D-M^{\prime}$, mercadoria - dinheiro - mais mercadoria, mas uma troca D - M - D', di- nheiro - mercadoria - mais dinheiro ou lucro. Há, assim, um excedente puramente monetário, o lucro, para o qual era preciso dar um destino, porque o próprio fluxo circular da produção não contém dentro dele demanda para permitir a venda de toda a produção. A análise de Marx se completa com a teoria da desproporção, que é uma outra forma de exprimir a capacidade da economia de absorver toda a produçáo. Para isso, Marx dividiu a economia capitalista em dois setores: Departamento I, produtor de bens de capital; e Departamento II, produtor de bens de consumo. $\mathrm{Na}$ fase de expansão, o Departamento I, que no período de declínio quase se paralisara, tende a crescer mais rapidamente do que o Departamento II. O crescimento mais moderado deste está relacionado ao caráter mais estável da demanda de bens de consumo, mas é também causado pelo crescimento mais lento dos salários do que dos lucros na primeira fase da expansão e, em consequência, de um crescimento insuficiente da demanda de bens de consumo por parte dos trabalhadores. Depois que a demanda reprimida de bens do Departamento I é atendida, a continuidade do seu crescimento a um ritmo maior do que o do Departamento II provocará a superprodução e, em seguida, a paralisação dos investimentos no Departamento I, desencadeando a reversão cíclica.

Dois economistas tiraram dessa segunda tese de Marx sua teoria fundamental: Rosa de Luxemburgo e John M. Keynes. A primeira, no quadro do marxismo, percebeu que, entendido o sistema capitalista como um sistema fechado, consumidores e investidores não constituiriam demanda suficiente para a continuidade do processo de acumulaçáo. Ela resolveu o problema com sua teoria do imperialismo, aproveitando-se da trilha que havia sido antes aberta por John Hobson (1902) e por Lenin (1917): as colônias funcionavam como novos mercados para serem ocupados pela produção e pelo capital excedente - sem aplicação rentável nos países centrais. Na mesma direção, outra "saída externa” para o capitalismo foram as despesas de guerra.

Mas o capitalismo superou a crise causada pela Primeira Guerra Mundial, e as teorias de estagnação secular perderam força. Entretanto, quando o regime econômico liberal, que desde os anos de 1830 imperava no mundo rico, entrou em colapso em 1929, 
o problema voltou. E quem o retomou de maneira genial foi Keynes. Já no primeiro capítulo da Teoria geral ele fez a crítica da Lei de Say, a lei do fluxo circular da produção, segundo a qual toda produção se transforma em lucro ou salário; estes necessariamente se transformam em investimento ou em consumo e, dessa forma, a oferta criaria sua demanda. Keynes viu que a tese era absurda do ponto de vista empírico e encontrou uma explicaçáo para o fato de que a oferta não cria sua demanda de maneira plena - o fato já percebido por Marx de que na economia capitalista é possível entesourar o dinheiro. Keynes conhecia a teoria de Marx e, em um trabalho preparatório à Teoria geral, referiu-se de maneira elogiosa ao sistema D - M - D'. Mas Keynes não deduziu daí a estagnação secular, mas simplesmente a tendência às crises econômicas e financeiras cíclicas, as quais uma política fiscal e monetária poderia moderar. Paul Sweezy, em seu extraordinário livro Teoria do desenvolvimento capitalista ([1956] 1962), associou Rosa de Luxemburgo a Keynes. Para ele, "como o incremento do consumo capitalista é uma proporção decrescente da acumulação total, segue-se que a taxa de crescimento do consumo declina em relaçáo à taxa de crescimento dos meios de produção" (Idem, p. 222). Sweezy dedicou um capítulo inteiro de seu livro às forças contrabalançadoras da tendência ao subconsumo e concluiu que elas evitavam a estagnação secular, mas não as crises cíclicas.

Durante os Anos Dourados do Capitalismo, que também foram os anos keynesianos, as teorias da estagnação secular voltaram a ser deixadas de lado, senão esquecidas, não apenas porque o crescimento foi forte e náo houve aumento das desigualdades, mas também porque as crises quase desapareceram. Voltaram, entretanto, a ser debatidas após a crise financeira global de 2008. Ficou claro então que desde o final dos anos de 1970, sob o domínio político de uma coalizão de classes financeiro-rentista, o capitalismo vinha apresentando baixo crescimento e voltara à alta instabilidade financeira pré-keynesiana. Nesse quadro, duas contribuiçóes de economistas relativamente ortodoxos, destacaram-se: as de Lawrence Summers (2014) e a de Robert J. Gordon, que é o objeto desta resenha.

Lawrence Summers, em conferência de 2014, sugeriu que os países ricos não estão mais simples- mente enfrentando um mero ciclo econômico, existindo sinais de que estaríamos diante de um problema de estagnação secular. Nas suas palavras: "Primeiro, os Estados Unidos e as outras economias industriais estão atualmente enfrentando dificuldade em alcançar simultaneamente crescimento adequado, utilização de capacidade, e estabilidade financeira. Segundo, isto deve estar relacionado com uma grande queda na taxa natural de juros reais”. Ele justifica essa dificuldade com vários dados: o produto potencial caiu, a relação emprego-população de pessoas entre 25 e 54 anos vem caindo, a queda da produtividade total de fatores vem sendo causada pela diminuição do investimento em vez da diminuição do progresso técnico, a inflação não se acelerou apesar do aquecimento da economia entre 2002 e 2007. Esse aquecimento decorreu de uma bolha de crédito para a construção de residências em vez do aumento do investimento na produção. Enfim, Summers não conseguiu encontrar nenhum período de crescimento satisfatório desde o início do século nos Estados Unidos e nos demais países ricos.

Como explicar essa queda da taxa de juros? Essencialmente porque, primeiro, houve diminuição da demanda de investimentos financiados por dívida. Os casos do Google e do Facebook são paradigmáticos em relação a esse problema. Segundo, o declínio da taxa de crescimento da população também causa a diminuiçáo da demanda por investimentos. Terceiro, a concentração da renda na camada mais alta aumentou a propensáo a poupar e aumentou os lucros retidos das empresas. Quarto, os preços relativos dos bens de capital caíram em relação aos demais preços. Por fim, houve um grande aumento das reservas internacionais dos países, o que também significou diminuição dos investimentos.

Para Summers, esses cinco fatores contribuíram para reduzir os investimentos que, por sua vez, causaram a queda da taxa de juros. Será essa uma teoria da estagnação secular? Para que fosse, seria necessário, seguindo Ricardo e Marx, que a taxa de lucro esperada pelas empresas estivesse caindo, mas não foi isto que aconteceu. Conforme Summers mostra, a taxa de lucro, que caiu nos anos de 1970 e, depois de uma recuperação, voltou a cair moderadamente nos anos de 1990, vem subindo desde o início dos anos de 2000. Mas isso não levou as empresas a investir 
mais. Dessa maneira, a causa básica dos investimentos - uma diferença satisfatória entre a taxa de lucro esperada e a taxa de juros - não vem sendo confirmada na prática. As empresas investem pouco, não obstante os lucros aumentem e os juros caiam.

\section{Do lado da oferta}

Nos anos de 1980, no livro, Lucro, acumulação e crise, eu examinei pelo lado da oferta o problema da estagnação secular e o da desigualdade funcional (entre lucros e salários) à luz da teoria da taxa de lucro declinante de Marx. A queda da produtividade do capital ou da relaçáo produto-capital, nessa teoria, acontece porque o progresso técnico é "dispendioso de capital", ou seja, porque as empresas adotam novos tipos de máquinas que substituem novos tipos de trabalho - máquinas que são mais eficientes do que o trabalho substituído, mas são menos eficientes do que as máquinas que substituíram os tipos de trabalho anteriores, de forma que, afinal, depois que todos os concorrentes imitassem a empresa que primeiro adotou o novo tipo de máquina, a relação produto-capital total ou produtividade do capital cairia. Mas isso náo aconteceu nos países ricos a partir de 1870 , porque o progresso técnico passou a ser neutro, na medida em que um outro tipo de progresso técnico - "poupador de capital”, que resulta da substituição de máquinas velhas que substituem um determinado tipo de trabalho por máquinas mais modernas ou eficientes que substituem esse mesmo tipo de trabalho - passou a ser suficientemente importante para compensar o progresso técnico dispendioso de capital e tornar o progresso técnico neutro, com a relação produto-capital constante.

$\mathrm{Na}$ teoria de distribuição dos economistas clássicos, a taxa de salários permanece no nível de subsistência. Historicamente, porém, não foi isso o que aconteceu. A partir de 1870 os salários passaram a crescer aproximadamente à mesma taxa da produtividade. Por isso eu inverti a teoria da distribuição clássica e dividi a história do capitalismo em fases, segundo o comportamento do progresso técnico e o consequente comportamento da taxa de lucro. Inverter a teoria da distribuição dos economistas políticos clássicos significou reconhecer que os salários não permaneceram constantes ao nível de subsistência, como assumiam os clássicos; ao invés, considerei a taxa de lucro como dada, porque ela só deixará de ser positiva e satisfatória quando for encontrado um novo sistema econômico superior ao capitalismo. Enquanto isso não acontecer, a queda na produtividade do capital combinada com taxa de lucro constante poderá ser compensada pelo crescimento dos salários abaixo do crescimento da produtividade e, portanto, pelo aumento da desigualdade. Dessa maneira, a taxa de lucro continuará satisfatória para as empresas, elas continuarão a investir e a estagnação secular prevista não ocorrerá, enquanto os salários tenderão a estagnar.

Ao terminar de escrever meu livro, no início dos anos de 1980, o mundo rico acabara de experimentar os Anos Dourados do Capitalismo, e eu acreditei que isso se devia ao fato de que computadores cada vez mais baratos estavam tornando o progresso técnico poupador de capital, tornando a relação produto-capital cada vez maior. Não percebi, então, que, com a Terceira Revolução Industrial, estava ocorrendo uma grande substituição de novos tipos de trabalho por novas máquinas - o que caracterizava diminuição da produtividade do capital. Por isso não previ que nos anos neoliberais ou financeiro-rentistas do capitalismo (1979-2008) as taxas de crescimento cairiam, os salários dos trabalhadores estagnariam, e o $1 \%$ mais rico da população se tornaria muito mais rico. Não previ a grave crise que enfrenta hoje o capitalismo, definida por baixo crescimento, instabilidade financeira, e aumento da desigualdade que não apontam para a estagnação secular, mas para uma sociedade em que as insatisfaçôes e a instabilidade política são crescentes.

\section{Visão de Gordon}

A visão de Robert J. Gordon do problema é bem diferente. É uma análise do lado da oferta, mas nada tem a ver com o modelo da tendência à queda da taxa de lucro que sumarizei. Ele interessou-se pelo problema da estagnação secular já em 1999, quando assinalou que a produtividade nos Estados Unidos e nos demais países ricos baixara fortemente desde meados dos anos de 1970. Em um trabalho 
mais aprofundado, em 2012, "Is U.S. economic growth over? Faltering innovation confronts the six headwinds", Gordon deixou clara sua tese estagnacionista ao questionar o pressuposto que se tornou dominante no mundo desde a Segunda Guerra Mundial, que o desenvolvimento econômico seria um processo contínuo que persistiria para sempre. "Na verdade, não houve praticamente crescimento antes de 1750 , e não há garantia que o crescimento continuará indefinidamente. Ao invés, sugiro que o crescimento rápido dos últimos 250 anos provavelmente será um episódio único na história da humanidade" (Gordon, 2012, p. 1).

Em The rise and fall of American growth (2016) Gordon desenvolve e aprofunda sua tese. É um livro grande (760 páginas), para o qual ele contou com o apoio de uma equipe de auxiliares de pesquisa. Seu subtítulo, "O padrão de vida americano desde a Guerra Civil”, deixa claro que ele entende desenvolvimento econômico como aumento do padrão de vida e que vê sinais fortes de estagnação porque o padrão de vida estaria deixando de aumentar. Que o crescimento tenha diminuído desde meados dos anos 1970, não há qualquer dúvida. Mas é possível falar em estagnação secular? Vejamos como argumenta o autor.

Gordon vê o século que começa em 1870 como um "século especial", porque foi um período de grande crescimento para os Estados Unidos, mas o intervalo entre 1920 e 1970 - que ele denomina o "Grande Salto" - foi ainda mais dinâmico. Nos três períodos que ele analisa - 1870-1920, 1920-1970 e 1970-2014 - a taxa de crescimento anual da renda por pessoa foi, respectivamente, de 1,84, 2,41 e $1,77 \%$ ao ano. A queda da taxa de crescimento em relação ao Grande Salto é grande, mas insignificante em relação ao período 1870-1920, de forma que não vejo estagnação ou tendência à estagnação nesses números. Gordon, porém, argumenta que as horas trabalhadas por pessoa caíram $0,41 \%$ ao ano no segundo período, voltando a aumentar $0,15 \%$ ao ano no terceiro período. Essa queda deveu-se à luta dos trabalhadores por uma jornada menor e à legislação do New Deal, que reduziu adicionalmente as horas trabalhadas e deu mais poder aos sindicatos. Em seguida, Gordon divide o aumento da produção por pessoa em três componentes ou causas - educaçáo, aprofundamento do capital e produtividade total dos fatores - e verifica que o forte aumento no período do Grande Salto deveu-se ao aumento da produtividade, que não se repetiu no período seguinte.

Gordon assinala que esses dados parecem contradizer a designação de "século especial" que ele deu para o período 1870-1970. O grande crescimento começa em 1870 e não em 1920, porque, como ele assinala em todo o livro, foi a partir de 1870 que um grande número de inovaçóes mudou radicalmente para melhor os padróes de vida dos americanos e europeus. Mas ele tem uma resposta para defender seu século especial, a partir da contribuição de Paul David: a revolução da eletricidade, em 1882, foi mais importante do que a revolução dos computadores no após Segunda Guerra Mundial, mas não aconteceu de um dia para outro: "a explicação principal é a de Paul David, que fez bem conhecida analogia entre a evolução da maquinaria elétrica e a do computador eletrônico... Para ele, houve um longo período de gestação entre a invençáo da eletricidade e o resultado em termos de desenvolvimento econômico: quatro décadas" (p. 17). David atribuiu essa demora às dificuldades em desenvolver as máquinas elétricas e também à forte queda do preço da eletricidade que só ocorreu nos anos de 1910.

É interessante que a Grande Depressão dos anos de 1930 não impediu o Grande Salto. Pelo contrário, como ele argumenta no capítulo 16 do livro, "a operação normal da economia, que foi obscurecida pela Grande Depressão, foi seguida pelo milagre econômico da Segunda Guerra Mundial...” e pelo crescimento nos anos de 1950 e 1960 que "claramente excedeu o que seria esperado com base na análise das tendências nas seis décadas anteriores a 1928” (p. 536). Para Gordon, o Grande Salto deve ser explicado a partir de uma perspectiva de longo prazo, pelas inovaçóes que são desencadeadas com a invenção da eletricidade e do motor a explosão, pelo aumento do poder dos sindicatos durante o New Deal e pela aceleração das invençôes e inovaçôes que ocorreram em plena Grande Depressão, os três fenômenos desembocando na Segunda Guerra Mundial. E sintetiza Gordon: "O caso para interpretação do 'apoio econômico' para a Segunda Guerra Mundial é muito forte, expressando-se em todas as dimensóes, desde a educação até a Lei GI 
sobre a elevaçáo da despesa pública financiada por deficits que deu à nova classe média capacidade de comprar os bens de consumo que a Segunda Revolução Industrial proporcionou" (p. 537).

Mas voltemos ao início do livro. Ainda na Introdução, Gordon define seu objetivo principal: "fazer uma avaliação quantitativa e qualitativa das mudanças no padráo de vida que melhoraram muito o bem-estar social" (p. 20). A grande virada no padrão de vida da população americana aconteceu a partir de 1870. Nessa época, "a vida das donas de casa era caracterizada por trabalho estafante, e dos maridos, por trabalho perigoso e extenuante. A vida era curta, famílias grandes se apinhavam em casas pequenas, boa parte da comida e do vestuário era produzido em casa" (p. 28). De 1870 a 1940, o grande avanço no padrão de vida da família trabalhadora americana não aconteceu na alimentação e no vestuário, mas nas casas, que aumentaram de tamanho e passaram a ser conectadas às redes de suprimento de água encanada, de eletricidade, de esgotos, de gás e, afinal, de telefones. Vemos, ao mesmo tempo, uma rápida e ampla difusão dos bens de consumo durável - o automóvel, os rádios, os refrigeradores, as máquinas de lavar, que aliviaram enormemente o trabalho das donas de casa. Os índices de leitura também aumentam extraordinariamente, em particular a leitura de revistas e de livros. Os indicadores sociais também melhoram de maneira radical: cai a mortalidade infantil, aumenta a expectativa de vida, diminui o trabalho infantil e juvenil, cai o número de horas trabalhadas, os níveis de educação aumentam enormemente.

O período de 1940 a 1970 foi de transiçáo e é tratado no capítulo 10. É o momento do consumo de massa nos supermercados e nas lojas de departamento. Da alimentaçáo cada vez mais fora de casa. Do deslocamento da nova classe média para os subúrbios das cidades. Gordon conclui esse capítulo dizendo: "O ritmo do progresso econômico desde 1940 e, particularmente, desde 1970, não foi nem tão abrangente, nem táo revolucionário quanto foi entre $1870 \mathrm{e}$ 1940. Isto é evidente em relação às três necessidades básicas: habitação, vestuário e alimentação". (p.370)

Em seguida, Gordon dedica-se a descrever a civilizaçẫo do automóvel, do transporte aéreo, dos divertimentos (principalmente o cinema, a televisão, os discos ou CDs) e a revoluçáo das comunicaçôes, com o computador, os e-mails, a Internet, o telefone celular, o streaming, os avanços na medicina, o sistema de cuidados de saúde. E se aproxima da conclusão pessimista da estagnação secular, porque os "ventos contrários ao desenvolvimento" passam a soprar mais fortes. O mais grave deles é o vento da desigualdade. Os outros dois ventos que estão reduzindo a taxa de crescimento do padráo de vida dos americanos são a educação, que não melhora como devia, a demografia definida pelo envelhecimento da populaçáo, o aumento da dívida do Estado, e, ainda, a globalização, o aquecimento global e o aumento da poluição.

Contra esses ventos maus, o que fazer? Gordon discute a questão no capítulo 18 - o último do livro. "O Estado estimular a inovação é pouco promissor, porque a máquina americana de realizá-las continua saudável. Há pouco espaço, também, para se estimular investimentos, porque depois de anos de política monetária frouxa e lucros elevados tornaram disponíveis para investir mais recursos do que as empresas decidem usar" (p. 643). Gordon aposta mais na educação e em medidas contra a desigualdade, principalmente impostos progressivos no topo e aumento do salário mínimo e sistema de renda básica na base da sociedade. Mas, de qualquer forma, ele náo acredita que a economia americana volte a crescer fortemente. No capítulo anterior ele mostra que a taxa de crescimento da economia americana caiu substancialmente - algo que é bem conhecido. Entende que a causa direta deste fato é a queda da taxa de aumento da produtividade - do crescimento da produtividade total dos fatores. Enquanto esta cresceu a uma taxa anual de $1,8 \%$ entre 1920 e 1970 , de 2004 a 2014 cresceu apenas $0,4 \%$ ao ano. A Terceira Revolução Industrial, a revolução da tecnologia da informação e da comunicaçáo, não teve forças para manter o crescimento da produtividade em um nível satisfatório. Gordon cita Robert Solow (1987) a respeito do problema: "Podemos ver computadores em toda parte, menos nas estatísticas de produtividade" (p. 577). E Gordon oferece sua explicação:

Embora a Terceira Revolução Industrial tenha sido de fato revolucionária, seus efeitos foram sentidos apenas em uma esfera limitada da ati- 
vidade humana, em contraste com a Segunda Revolução Industrial, que mudou tudo. Categorias de despesas de consumo pessoal que não foram influenciadas pela tecnologia da informação e da comunicação foram as compras de alimentos no lar e fora do lar, vestuário e sapatos, automóveis e energia para movê-los, móveis, suprimentos para a casa, eletrodomésticos. Em 2014, dois terços das despesas de consumo foram para serviços, incluindo aluguel, saúde, educação, e cuidado pessoal (p. 578).

A partir dessas consideraçóes, temos em Robert Gordon uma teoria da estagnação secular mais convincente do que a proposta por Larry Summers? Este não soube explicar como os lucros continuam elevados enquanto o capitalismo caminha para a estagnação. Gordon também não tem uma previsão de queda da taxa de lucros, reconhece que estes estão altos, e não vê as empresas aumentarem seus investimentos. Sua tese central é o fato de que as inovaçóes da Segunda Revolução Industrial, desde os sistemas de luz e água encanada nas residências até o automóvel e as viagens aéreas, foram mais impactantes em termos de melhoria de qualidade de vida, do emprego e, também, em termos da necessidade de aumentar os investimentos, do que as inovaçôes da Terceira Revolução Industrial. Isso é muito bem observado, especialmente em relação aos investimentos, que, nos países ricos, realmente não vêm se sustentando em um nível elevado desde os anos de 1970. As máquinas não param de substituir os trabalhadores, mas a produção não implica investimentos que a tornem cada vez mais capital-intensiva, como seria de esperar.

Gordon parece esquecer o problema da demanda quando afirma que as empresas náo mostram disposição de investir mais sem explicar por quê. E, no entanto, o problema keynesiano da tendência à insuficiência de demanda é fundamental. Quando há falta de investimentos é sinal de que há falta de demanda em relação à oferta de capitais. E essa falta de demanda se agrava porque a substituição de trabalhadores por máquinas, em vez de tornar a produção capital-intensiva, a torna crescentemente conhecimento-intensiva - o que favorece os ordenados dos tecnoburocratas, não os salários dos trabalhadores, que, estes sim, tendem a estagnar.

\section{Três análises de esquerda}

Como a esquerda vê o problema da estagnação secular? Michel Aglietta, da Escola da Regulação Francesa, em resenha do livro de Gordon na New Left Review (2016, p. 124), não ficou convencido pelos argumentos apresentados. Para ele, é provável que um novo ciclo de inovaçóes aconteça, tendo como eixo os grandes investimentos necessários para fazer frente ao aquecimento global e à poluição ambiental. Aglietta prevê que a liderança do processo caberá à China: "A revolução industrial que será necessária para mitigar os danos ambientais e adaptar habitats hostis envolveria bens públicos transnacionais, investimentos pesados e instituiçóes para lidar com novos riscos sistêmicos. A China não só tem uma necessidade aguda, mas também os recursos financeiros e a vontade política de alocar grandes reservas de poupança para essa prioridade suprema”. Wolfang Streeck (2014), na mesma revista, é menos otimista. Para ele três tendências negativas levarão o capitalismo ao colapso: o aumento da dívida pública e da dívida privada (dos consumidores); o aumento da desigualdade; a instabilidade financeira. Muitas vezes, diz ele, se previu o fim do capitalismo, mas desta vez o quadro é diferente "porque seus mais notáveis técnicos não sabem como torná-lo saudável novamente... A imagem que eu tenho do fim do capitalismo - um fim que, acredito, está já em marcha - é o de um sistema social em crônico desarranjo, por razóes que lhe são internas e são independentes da existência de uma alternativa viável” (pp. 46-47). Cinco desordens sistêmicas definem esse desarranjo crônico: a estagnação, apoiando-se em Summers e Gordon; a plutocracia, na medida em que não há perspectiva de que a tendência ao aumento da desigualdade será interrompida; a pilhagem do património público; a fraude e a corrupção, que, conforme Max Weber, sempre andaram junto com a cobiça; e a falta de um "centro seguro", ou seja, de uma potência hegemônica que assegure a ordem, dada a perda de poder dos Estados Unidos. O trabalho de Streeck é fascinante, mas não dá conta de seu título: não é uma teoria do fim do capitalismo; é simplesmente uma crítica aguda do capitalismo.

Immanuel Wallerstein (2017, pp. 53-54) também pretende ter uma teoria do colapso. Ele acredita 
que todo sistema e, portanto, o capitalismo (que ele chama "sistema-mundo") segue uma trajetória necessária constituída de "três fases: nascimento, longo período de funcionamento normal, e inevitável crise estrutural". E conclui que o capitalismo já chegou a esta última fase "porque os custos de produção aumentaram de maneira regular em relação aos preços praticados no mercado (demanda efetiva)". Mas essa explicação é muito estranha. Como a produtividade aumenta no capitalismo ou, em outras palavras, como o capitalismo até hoje náo deixou de apresentar aumento da renda por habitante, os custos de produção diminuem, e os preços também diminuem. Mais interessante é sua tese de que os ciclos longos dentro da fase normal "terminam sempre com a formação de uma quase-monopólio; ora, os quase-monopólios são necessariamente limitados no tempo, porque terminam por se autodestruírem". Isso é verdade, mas eles apenas enfatizam o caráter cíclico e inerentemente instável do capitalismo.

\section{Como ficamos, entáo?}

Como ficamos, então, com a estagnação secular? A queda da taxa de lucro prevista por Ricardo e por Marx, que produzia a estagnação, não ocorreu. A taxa de lucro continua satisfatória no mundo capitalista. $\mathrm{O}$ aumento da produtividade do trabalho também não foi interrompido. Teríamos, então, a estagnação combinada com taxa de lucro satisfatória e aumento da produtividade do trabalho, mas sem aumento dos investimentos e sem salários crescentes? É possível uma equação desse tipo? Sim, é possível, desde que acrescentemos uma variável a essa equação: um brutal aumento do poder de monopólio das empresas em função de um incessante processo de aquisiçóes e fusôes, através do qual as grandes empresas compram seus concorrentes e reduzem a competição. Essa é a lógica do "capitalismo monopolista", já prevista por Marx, e que teve sua análise definitiva realizada por Paul Baran e Paul Sweezy ([1966] 1968). Antes e depois de 1966, o processo de aumento do grau de monopólio no capitalismo não deixou um momento de crescer. Dessa maneira, é possível haver baixo investimento e taxa de lucro alta, porque esta não reflete novas e boas oportunidades de investimento que surgem do aumento da demanda, mas, simplesmente, reflete o poder de monopólio das empresas.

Esse problema se agrava na medida que esse capitalismo monopolista vem, a cada dia, deixando de ser um capitalismo de empresários que inovam e buscam o lucro, para ser um capitalismo de rentistas e financistas que querem elevados dividendos e juros, e um capitalismo de altos executivos ou tecnoburocratas cujos bônus refletem os resultados de curto prazo da empresa, ao invés de refletirem o seu crescimento e o crescimento dos lucros no médio prazo. Dessa maneira, as empresas adotam um radical curto-prazismo, caracterizado pela distribuição de dividendos que aumente o valor da empresa no mercado financeiro, em vez de aumentar sua capacidade de produção e seu lucro.

Soma-se a isso o fato que o mundo rico enfrenta hoje uma brutal abundância de capitais, que é consequência de um processo de acumulação que não para desde a Segunda Guerra Mundial. Antes tínhamos o mesmo processo de acumulação, mas, de tempos em tempos, o estoque de capital acumulado era destruído por grandes crises econômico-financeiras, como as de 1873 e de 1929, ou entâo por grandes guerras, como a de 1914 e a de 1939. Como Thomas Piketty (2013) observou, desde 1945 não temos grandes guerras e não temos grandes crises; não temos, portanto, saudáveis destruiçóes de capital que mantenham o equilíbrio entre a oferta e a demanda de capitais. A crise financeira global de 2008 poderia ter sido uma grande crise, poderia ter sido um episódio de eliminação de capitais, se não houvesse ocorrido a forte resposta contracíclica keynesiana, que limitou sua extensão. Existe, assim, um imenso excedente de poupança, um savings glut, na expressão de Ben Bernanke (2005), em busca de oportunidades de investimento que não materializam.

Como dar vazão a essa abundância ou excesso de capitais acumulados? Já vimos que Robson e Lenin deram uma primeira resposta a essa pergunta: desde o final do século XIX, o imperialismo moderno, ou seja, a ocupação dos mercados internos dos países em desenvolvimento pelos capitais dos países ricos, vem sendo uma maneira de escoar esse enorme excedente de capitais. Esse processo continua ativo até hoje. A diferença econômica foi que 
a ocupação dos mercados dos países da periferia do capitalismo pelo comércio e pelo financiamento em moeda estrangeira tornou-se menos importante do que a realizada pelas empresas multinacionais.

Desde os anos de 1980, com as privatizaçóes da primeira-ministra britânica, Margareth Thatcher, surgiu uma segunda maneira: o capital rentista moveu-se em direção aos grandes serviços públicos monopolistas de energia, transporte e comunicaçóes. Esses serviços antes eram reservados para o Estado, porque exigiam capitais muito elevados e porque os consumidores exigiam preços moderados para eles. Porém, desde que o capital rentista passou a ser muito mais alto do que o capital empresário, a nova coalizão dominante, financeiro-rentista - associando capitalistas rentistas, financistas e dirigentes das grandes empresas - tornou-se dominante e percebeu que os grandes serviços monopolistas seriam uma excelente aplicação de seu capital desde que, naturalmente, os preços fossem elevados. E começou, então, a partir dos anos de 1980, uma grande onda de privatizaçóes desses monopólios que, como já acontecia há tempo com as empresas privadas, passaram a ser dirigidas por altos executivos em nome dos capitalistas rentistas.

Por fim, foi encontrada uma terceira maneira de dar vazão ao excesso de capitais privados: o endividamento público e o endividamento privado, que Streeck salientou com muita propriedade. $\mathrm{O}$ endividamento público não para de aumentar nos países ricos, menos devido a gastos correntes excessivos e mais devido ao fato de que o Estado é sempre chamado a socorrer os bancos e as grandes empresas nos momentos de crises cíclicas. $\mathrm{O}$ endividamento privado também é crescente, porque as elites liberais, financeiro-rentistas, deram-se conta de que uma alternativa para aumentar salários para garantir a demanda é aumentar o endividamento das famílias. Foi essencialmente esse fato que levou à crise financeira global de 2008.

\section{Conclusão}

O capitalismo enfrenta, portanto, uma crise de baixo crescimento e instabilidade tanto do lado da oferta como do lado da demanda. Do lado da demanda, para resolver o problema do excesso de capitais, as políticas keynesianas continuam funda- mentais, mas elas estáo limitadas aos momentos de crise econômica. Fora de crises, as elites financeiro-rentistas adotam as estratégias já referidas - o curto-prazismo financeiro e as quatro formas de dar vasão ao excesso de capitais: imperialismo; privatizaçóes dos monopólios públicos; aumento da dívida pública; aumento da dívida dos consumidores. Essas cinco estratégias são intrinsecamente perversas, porque, em vez de envolverem o aumento dos investimentos, envolvem o aumento constante do poder de monopólio e da desigualdade nos países ricos e o prejuízo nos países em desenvolvimento. Os beneficiários são uma pequena mas poderosa classe de capitalistas rentistas, financistas e altos executivos.

Mas é preciso também ver o problema do lado da oferta. Deste lado, o baixo crescimento e o aumento da desigualdade podem ser explicados pela queda da produtividade do capital prevista por Marx, ou pela tese de Gordon da superioridade das inovaçóes e do aumento da produtividade que elas causaram na Segunda Revolução Industrial, quando comparadas com as inovaçôes às da Terceira Revolução Industrial. Em relação à queda relativa da produtividade do capital, é preciso considerar o caráter dispendioso de capital do progresso técnico ou a queda da produtividade do capital que estamos vendo desde os anos de 1970. A relação produto-capital cai não obstante o preço dos computadores tenha caído muito - o que indicaria aumento da produtividade do capital. Cai porque a Terceira Revolução Industrial - a revolução da tecnologia da informação e da comunicação - está envolvendo a substituiçáo de novos tipos de trabalho por novos tipos de máquinas, as quais são mais eficientes do que o trabalho, mas menos eficientes do que os tipos anteriores de máquinas que substituíram tipos anteriores de trabalho. Houve, inicialmente, uma grande substituição de trabalho de escritório; depois, de trabalho bancário através dos caixas eletrônicos; agora, uma imensa substituição de novos trabalhos pelos robôs. As novas máquinas são suficientemente eficientes para justificarem sua compra e a substituição de novos tipos de mão de obra, mas são ineficientes quando comparadas com as máquinas adotadas anteriormente para substituir outros tipos de trabalho. Nesse tipo de progresso técnico, a relação produto-capital não para de cair, ou seja, a produtividade do capital é declinante, porque os no- 
vos processos produtivos (combinação de máquina e trabalhador) são mais eficientes do que o trabalho vivo, mas são menos eficientes do que os processos produtivos anteriores. Nessas condiçóes, para que a taxa de lucro não caia é necessário que os salários médios dos trabalhadores cresçam menos do que a produtividade ou então simplesmente estagnem. É o que vem acontecendo no mundo rico. Do lado da oferta, o progresso técnico dispendioso de capital está levando a um crescente aumento da desigualdade.

Pelo lado da demanda, a tendência à insuficiência de demanda e a ideia da armadilha da liquidez propostas por Keynes continuam a ser o problema básico; foi o problema salientado por Larry Summers ao analisar a incapacidade da política monetária - da taxa de juros - de restabelecer a demanda efetiva. Mas vimos que esse problema se agravou com o crescente excesso de capitais, com a desproporção entre a quantidade de capital acumulado e as oportunidades de investimento. Sempre se pode esperar que o aumento dos ordenados dos tecnoburocratas públicos e privados e o aumento do consumo destes e dos rentistas ocupem o lugar do aumento dos salários na garantia de demanda efetiva, mas é evidente que esse tipo de substituição de demanda tem fôlego curto. Também são perversas as estratégias inventadas para dar vazão ao excesso de capitais.

Tudo isso não está resultando na estagnação secular strictu sensu, mas em uma quase estagnação associada à quase estagnação dos salários, ao aumento da desigualdade e à redução da taxa de crescimento. E também em uma crescente insatisfação da população com a "globalização" - ou seja, com o capitalismo liberal financeiro-rentista dominante no mundo desde os anos de 1980. Haveria estagnação plena se os lucros estivessem caindo, mas os lucros continuam elevados, devido ao incessante aumento do poder de monopólio das grandes empresas. $\mathrm{O}$ que temos são salários crescendo muito pouco por causa da necessidade de manter a taxa de lucro satisfatória no quadro de inovaçóes dispendiosas de capital - inovações que, segundo Gordon, são inferiores às da Segunda Revolução Industrial.

E há ainda três fatos históricos novos, além da abundância de capitais, que pressionam os salários nos países ricos para baixo e levam o capitalismo atual a uma crise ao mesmo tempo grave e crôni- ca. Eu apenas os menciono para não estender esta resenha: a concorrência dos países em desenvolvimento com sua máo de obra barata, o aumento da imigração para os países ricos e o progresso técnico acelerado, que valoriza o trabalho qualificado e desvaloriza o não e o pouco qualificado.

\section{Bibliografia}

AGLIETTA, Michel. (2016), “America's slow down". New Left Review, 100: 119-128.

BARAN, Paul \& Paul SWEEZY. ([1966] 1968) Capitalismo monopolista. Rio de Janeiro, Zahar.

BERNANKE, Ben S. (2005) "The global saving glut and the US current account deficit". The Sandridge Lecture, 14 abr.

BRESSER-PEREIRA, Luiz Carlos. (1986), Lucro, acumulação e crise. São Paulo, Editora Brasiliense.

GORDON, Robert J. (1999), "US economic growth since 1870: One big wave?”. American Economic Review, 89 (2): 123-128.

(2012), "Is US economic growth over? Faltering innovation confronts the six headwinds". Robert J. Gordon NBER Working Paper, n. 18315. . (2016), The rise and fall of American growth. Princeton (NJ), Princeton University Press.

PIKETTY, Thomas. (2013), Le capital au XXIme Siècle. Paris, Seuil.

SOLOW, Robert M, (1987) "Second thoughts on growth theory”, Robert M. Solow Prize Lecture (in the memory of Alfred Nobel, December 8, 1987), Boston: Kluwer Academic Publishers.

STREECK, Wolfgang. (2014), "How will capitalism end?”. New Left Review, 87: 35-66.

SUMMERS, Lawrence. (2014), "US economic prospect: secular stagnation, hysteresis, and the zero lower bound". Business Economics, 49 (2): 65-73.

SWEEZY, Paul M. ([1956] 1962), Teoria do desenvolvimento capitalista. Rio de Janeiro, Zahar.

WALLERSTEIN, Immanuel. (2017), La Gauche globale. Paris, Maison des Sciences de l'Homme.

\section{Luiz Carlos Bresser-Pereira é professor emérito da Fundação Getúlio Vargas. E-mail: bresserpereira@gmail.com.}

DOI: $10.17666 / 339607 / 2018$ 